\title{
The use of suicide gene systems in vascular cells in vitro
}

\author{
XU Ling Fei ${ }^{1}$, De Hua XU, Kai Ge, Zhong Cheng \\ ZHENG, LAN Y IN SUN, XIN YUAN LIU \\ Shanghai Institute of Biochemistry, Chinese Academy of \\ Sciences, Shanghai 200031, China
}

\begin{abstract}
To investigate the efficiency of suicide gene systems on vascular cells, HSV-tk/GCV and EC-CD/5-FC systems were established on vascular endothelial cells in vitro by retroviral transduction. Both modified cell lines were highly sensitive to prodrugs, the $\mathrm{IC}_{50}$ for GCV was less than $0.4 \mu \mathrm{M}$, and $\mathrm{IC}_{50}$ for 5 -FC was less than $75 \mu \mathrm{M}$, while the parental endothelial cells were insensitive even at the highest concentrations of prodrugs in this experiment. Mixed cellular assay showed that significant bystander effect was exhibited in modified endothelial cells. When only $10 \%$ or $30 \%$ of the mixed cells were tk positive and exposed to $20 \mu \mathrm{M} \mathrm{GCV}$ for 6 days, more than $60 \%$ or $90 \%$ of the whole population was killed. Similar result was also found in CD positive cells. These results indicated that both HSV-tk/GCV and EC-CD/5-FC systems could efficiently suppress endothelial cell growth in vitro.
\end{abstract}

Key words: Endothelial cell, suicide gene, HSVtk/GCV system, $E C-C D / 5-F C$ system, bystander effect.

\section{INTRODUCTION}

Recently, more and more evidences have shown that malignant solid tumor growth and metastasis are dependent on the formation of new blood vessels. These blood

1. Corresponding author

Abbreviations: ganciclovir (GCV); 5-fluorocytosine (5-FC); thymidine kinase ( $t k$ ); cytosine deaminase $(\mathrm{CD})$ 
Suicide gene systems in vascular cells

vessels also provide an entry site into the circulation for the neoplastic cells that detach from the tumor mass. Most solid tumors may neither grow beyond a diameter of $3-4 \mathrm{~mm}$ nor form metastasis if they are deprived of angiogenesis[1]. Thus, it seems reasonable that complete inhibition of angiogenesis might suppress the tumor growth and metastasis. Inhibition of tumor-induced angiogenesis was first proposed as an anticancer approach by Folkman in 1971[2]. In recent publications two strategies for inhibition of angiogenesis have been put forward, anti-angiogenesis and vascular targeting[3]. The key issue of the latter approach is direct destructing the vessels and infarcting areas of the tumor.

In this report, we investigated the possibilities of using suicide gene systems, both HSV-tk/GCV and EC-CD/5-FC, as a vascular targeting approach to suppress angiogenesis in vitro. It seems that few studies have been done to systematically investigate the efficiency of these suicide genes on endothelial cells.

\section{MATERIALS AND METHODS}

\section{Cell culture}

Murine pulmonary vascular endothelial cell 1Gll (gift from Dr. Dong Qiang-gang)[4] were cultured in the growth medium DMEM supplemented with $20 \%$ FCS, $2 \mathrm{mM}$ L-glutamine, $1 \%$ nonessential amino acids, $\operatorname{lm} M$ sodium pyruvate, $25 \mathrm{mM}$ HEPES, freshly added heparin and ECGS (From bovine neural tissue, Sigma) at the final concentration of $100 \mu \mathrm{g} / \mathrm{ml}$.

\section{Retroviral infection}

1 G11 cells were infected by incubating with recombinant retrovirus LtkSN or LCDSN $\left(1 \times 10^{4}\right.$ $\mathrm{cfu} / \mathrm{ml}$ ) in the presence of $8 \mu \mathrm{g} / \mathrm{ml}$ polybrene (Sigma) for $24 \mathrm{~h}$. Then the cells were cultured in the medium containing $800 \mu \mathrm{g} / \mathrm{ml} \mathrm{G} 418$ for 2 weeks. The representative G418 resistant clones $1 \mathrm{G} 11 / \mathrm{R}-\mathrm{tk}$ and $1 \mathrm{G} 11 / \mathrm{R}-\mathrm{CD}$ were selected for the further experiments.

\section{Cytotoxic assay in vitro}

The cytotoxicity of prodrugs was measured by MTT assay. Target cells were plated into 96-well microplates at 2,000 cells per well. Next day, cells were cultured in $200 \mu \mathrm{l} /$ well fresh medium containing various concentrations of prodrug. Six days later, medium was replaced with $180 \mu \mathrm{l}$ fresh medium containing $0.25 \mathrm{mg} / \mathrm{ml}$ MTT (Sigma). After $4 \mathrm{~h}$ of incubation at $37{ }^{\circ} \mathrm{C}, 100 \mu \mathrm{l}$ solubilizing reagent (20\% SDS and 50\% DMF in water) was added, then after another $4 \mathrm{~h}$, the $\mathrm{A}_{595}$ of each well was measured with a microplate reader with reference filter of $655 \mathrm{~nm}$. All tests were performed in six samples, and the percentage of survival was estimated as: \% Survival $=\mathrm{A} / \mathrm{B} \times 100 \%$ (A: mean value of $A_{595}$ from cells incubated with prodrug; B: mean value of $A 595$ from cells incubated with medium only.)

\section{Bystander killing effect}

Suicide gene positive and negative $1 \mathrm{G} 11$ cells were cocultured at 2,000 cells per well in 96-well microplates at ratios of 10:90, 30:70, 50:50, 70:30, 90:10. After $12 \mathrm{~h}$ incubation, $20 \mu \mathrm{M}$ GCV and $1,500 \mu M$ 5-FC were added, respectively. Six days later, the prodrug-mediated growth inhibition was measured.

\section{RESULTS}

Identification of the integration and expression of suicide genes 
(Data not shown)

\section{Prodrug-mediated growth inhibition in vitro}

The wild type $1 \mathrm{G} 11$ cells were used as control in the cytotoxicity assay. As shown in Fig la, the parental $1 \mathrm{G} 11$ cells were resistant to GCV even at the highest concentration $(200 \mu \mathrm{M})$ in the experiment. In sharp contrast, almost all the genetically modified cells (1G11/R-tk) were killed when incubated with only $20 \mu \mathrm{M}$ GCV for 6 days. The $\mathrm{IC}_{50}$ for GCV was only $0.4 \mu \mathrm{M}$. Similar results were found in $1 \mathrm{G} 11 / \mathrm{R}-\mathrm{CD}$ cells after 5-FC treatment. Transduction of $\mathrm{CD}$ gene made endothelial cells become highly sensitive to 5 -FC with the $\mathrm{IC}_{50}$ of $75 \mu \mathrm{M}$, while the control $1 \mathrm{G} 11$ cells were insensitive even they were exposed to $>10,000 \mu \mathrm{M} 5$-FC for 6 days (Fig lb). These data demonstrated that suicide gene systems, both HSV-tk/GCV and EC-CD/5-FC had significant killing effect on endothelial cells.
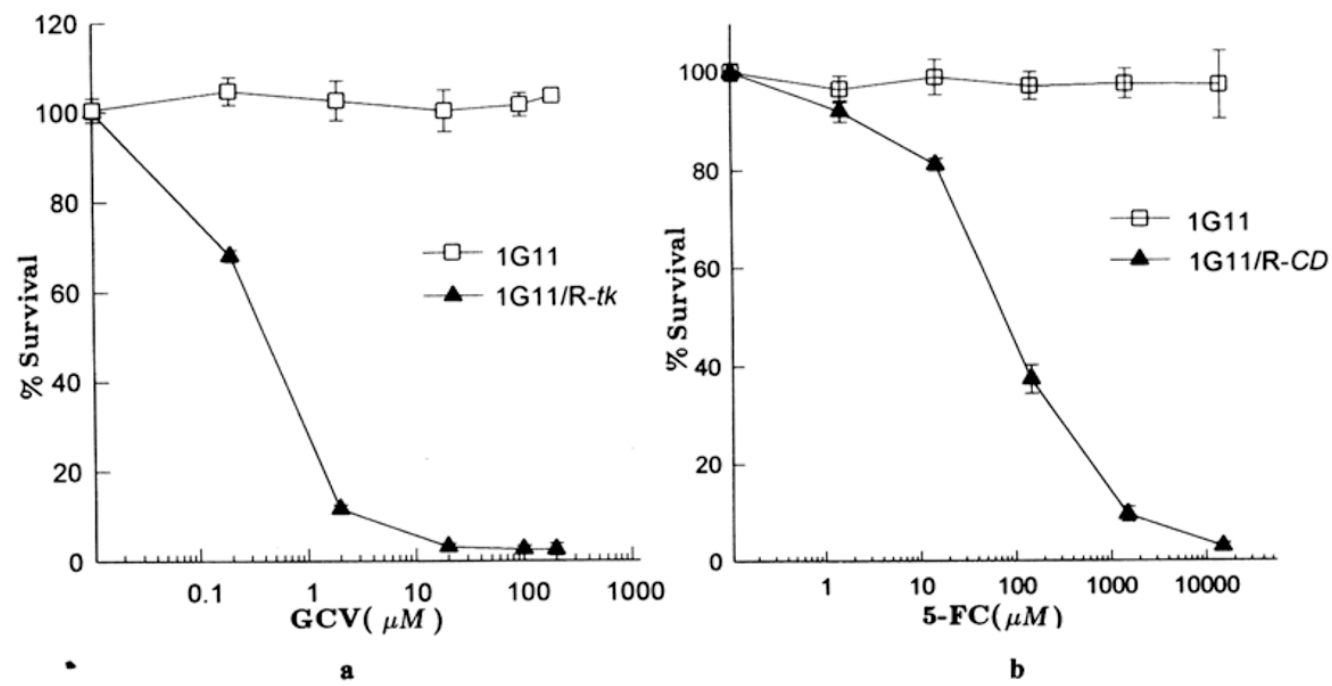

Fig 1. Prodrug-mediated growth inhibition in vitro. The cytotoxicity was determined by MTT assay. Each point represents the average \pm SD (bars) of five individualdeterminations. Logarithmic dose-response curves showed that all suicide gene modified $1 \mathrm{G} 11$ cells were highly sensitive to prodrugs while wild type 1G11 cells were insensitive. (a) GCV mediated growth inhibition. (b) 5-FC mediated growth inhibition.

\section{Analysis of the bystander killing effect in vitro}

The experiments were performed in which suicide gene positive and negative cells were mixed at varying ratios. The significant bystander effect was observed in both HSV-tk/GCV and EC-CD/5-FC systems. Fig 2a has shown that as few as $10 \%$ or $30 \%$ of the mixed cells were HSV-tk positive, more than $60 \%$ or $90 \%$ of the whole population was eradicated after they were exposed to $20 \mu \mathrm{M}$ GCV for 6 days. The Similar bystander effect was also found in EC-CD/5-FC system, though it was not 
Suicide gene systems in vascular cells

as significant as that in HSV-tk/GCV system. When CD positive and negative cells were mixed at ratio of $10: 90$ and cocultured in $1,500 \mu \mathrm{M} 5-\mathrm{FC}$, more than $50 \%$ of the population were killed in vitro (Fig $2 \mathrm{~b}$ ). Taken together, these results indicated that bystander killing effect might be used to kill the endothelial cells which were not transfected by suicide gene.
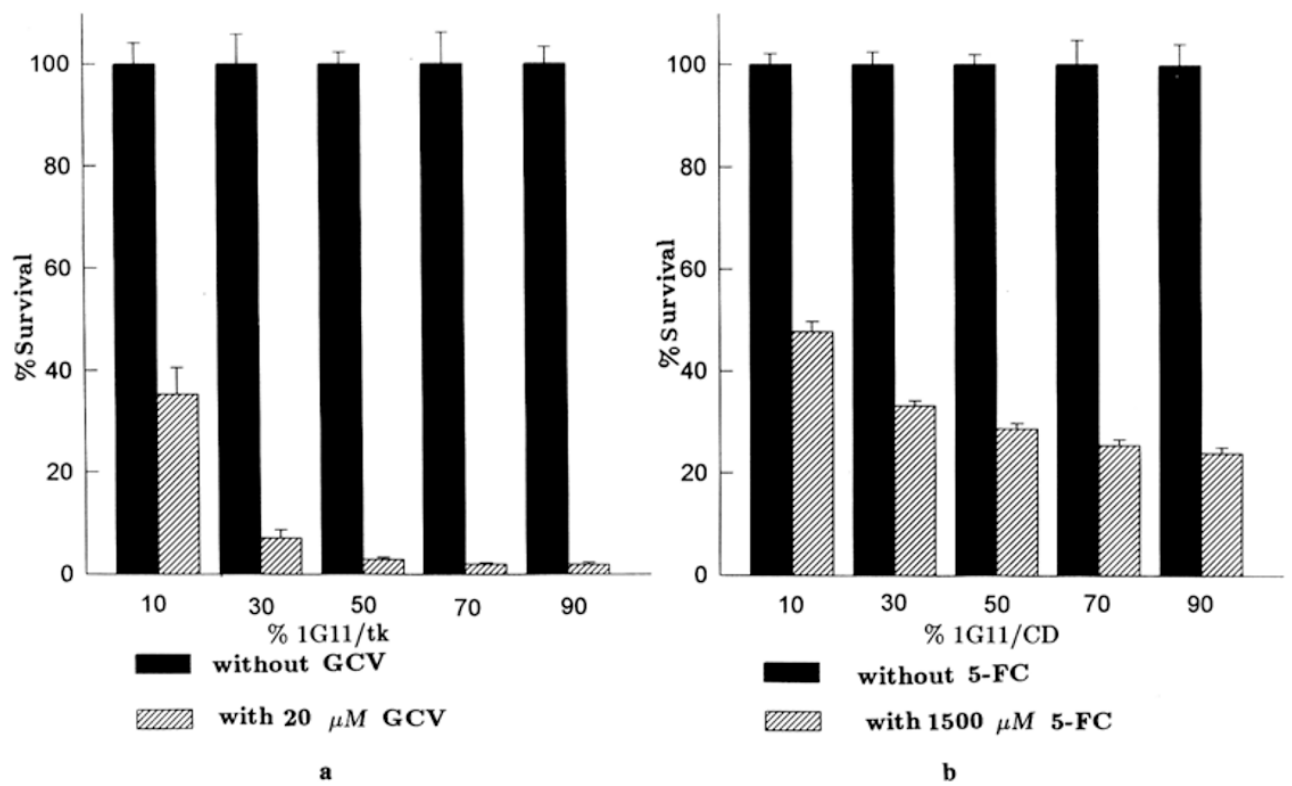

Fig 2. Analysis of the bystander killing effect in vitro. Suicide gene positive and negative 1G11 cells were mixed at varying ratios and prodrug-mediated growth inhibition was measured by MTT assay. Data represent: mean \pm SD (bars) of five samples. Significant bystander killing effect exhibited in both HSV-tk and EC-CD modified $1 \mathrm{G} 11$ cells. (a) Mixed 1G11/R-tk and 1G11 cells were exposed to $20 \mu M$ GCV for 6 days. (b) Mixed 1G11/R-CD and 1G11 cells were exposed to 1,500 $\mu$ M 5-FC for 6 days.

\section{DISCUSSION}

The importance of tumor angiogenesis in the process of solid tumor growth and metastasis has been widely accepted. Vascular endothelial cells provide the supply of nutrients for the growth of the primary tumor mass and the route of intravasation. Though not all angiogenic tumors produce metastasis, the inhibition of angiogenesis prevents the growth of tumor cells at both the primary and secondary sites and thus can prevent the emergence of metastasis[1]. In addition, destroying the blood vessels within tumor might result in the acute ischemic necrosis of the whole nourished area. Also, vascular endothelial cells are similar in different tumors, thus, make it possible to develop a general method for treating various types of cancer. 
In this study, we demonstrated the efficiency of using suicide gene systems, HSVtk/GCV or EC-CD/5-FC, on vascular cells in vitro by retrovirus transduction. All modified cells were highly sensitive to the prodrugs while the parental endothelial cells were insensitive even at the highest concentrations in the experiment. Significant bystander effect was also observed in the coculture assays, especially rather strong killing effect between $t k$ positive and negative endothelial cells.

Many studies have suggested that metabolic cooperation, involving the transfer of low molecular weight molecules between neighboring cells via gap junctions, could account for the bystander effect[5]. Though it has been reported that tumor-derived endothelial cells illustrated tight gap junctions similar to those seen in endothelial cells from normal tissues shown in electron microscopy[6], an analysis of patterns of junctional communication in skin showed that the endothelial cells of small blood vessels are coupled to surrounding stromal cells[7], and the endothelial cells of the vasculature of tumors are similarly coupled to the surrounding cells[8], which should allow toxic products generated by the suicide gene modified tumor cells to damage the blood supply[9]. Conversely, modified endothelial cells can also damage the surrounding tumor cells through its bystander killing effect and accelerate the tumor necrosis[10].

Endothelial cells in tumor blood vessels divide about 500 folds more rapidly than those in normal tissues which mostly represent a highly differentiated cell type[11, 12]. In theory, complete inhibition of angiogenesis should be well tolerated by most adult tissues. Due to the hyperproliferation status of endothelial cells in tumor blood vessels, retrovirus might be an ideal gene transduction vehicle since it could only infect the cells that were actively synthesizing DNA. Also, if cell-specific promoters or regulatory elements were used, the security of this approach might be increased. We have cloned the promoter region of the Fltl gene which has been shown to be almost exclusively expressed in endothelial cells[13] to obtain an endothelial cellspecific regulation element. Our further study will focus on this strategy.

\section{REFERENCES}

[1] Filder IJ, Ellis LM. The implication of angiogenesis for the biology and therapy of cancer metastasis. Cell 1994; 79:185-8.

[2] Folkman J. Tumor angiogenesis: therapeutic implications. N Engl J Med 1971; 285:1182-6.

[3] Fan TP, Jaggar R, Bicknell R. Controlling the vasculature: angiogenesis, anti-angiogenesis and vascular targeting of gene therapy. Trends Pharmacol. Sci 1995; 16(2):57-66.

[4] QG Dong, S Bernasconi, S Lostaglio, RW Calmanocici, IM Padura, F Breviario, et al. A general strategy for isolation of endothelial cells from murine tissues: characteri-zation of two endothelial cell lines obtained from murine lung and subcutaneous sponge implants. Arterioscleriosis, Thrombosis, and Vascular Biology, in press.

[5] Bi WL, Parysek LM, Warnick R, Stambrook PJ. In vitro evidence that metabolic cooperation is responsible for the bystander effect observed with HSV tk retroviral gene therapy. Hum Gene Ther 1993; 4(6):725-31.

[6] Robert RE, Thierry PC, Bruce RP, Margaret AB, Candace SJ, Ruth AM, et al. Gene therapy 


\section{Suicide gene systems in vascular cells}

and endothelial cell targeting for cancer. Ann NY. Acad Sci 1994; 176:257-64.

[7] John DP. Cancer gene therapy: a bystander effect using the gap junctional pathway. Mol Carcinogen 1994; 11:127-30.

[8] Pitts JD, Kam E, Morgan D. The role of junctional communication in cellular growth control and tumorigenesis. Modern Cell Biol 1992; 7:397-409.

[9] Culver KW, Ram Z, Wallbridge S, Ishii H, Oldfield EH, Blaese RM. In vivo gene transfer with retroviral vector-producer cells for treatment of experimental brain tumors. Science 1992; 256:1550-2.

[10] Ram Z, Culver K, Walbridge S, Blaese R, Oldfield E. In situ retroviral-mediated gene transfer for the treatment of brain tumors in rats. Cancer Res. 1993; 53:83-8.

[11] Folkman J. The role of angiogenesis in tumor growth. Semin Cancer Biol 1992; 3:65-71.

[12] Hobson B, Denekamp J. Endothelial proliferation in tumors and normal tissues: continuous labelling studies. Br J Cancer 1984; 49(4):405-13.

[13] Kaoru M, Daniel EJ, Lewis TW. A novel promoter for vascular endothelial growth factor receptor (flt-l) that confers endothelial-specific gene expression. J Bio Chem 1995; 270(46):27948-53.

Received July-18-1997. ～Revised Dec-15-1997. Accepted Dec-24-1997. 